\title{
Response to serotonergic and noradrenergic antidepressants: a crossover study of fluoxetine and desipramine in patients with first major depression episode
}

José Alfonso Ontiveros-Sánchez de la Barquera

Department of Psychiatry, University Hospital, Universidad Autónoma de Nuevo León; Instituto de Información e Investigación en Salud Mental A.C., Monterrey, N.L., Mexico

\begin{abstract}
Background: Response rate data from studies with different kinds of antidepressant drugs help in the development of guidelines for the rational prescription of pharmacotherapy. However, there are still few comparative studies with selective reuptake inhibition on serotonin or norepinephrine in the same sample of major depression patients. Methods: First episode major depression (DSM-III-R) outpatients who completed 6 weeks in two double-blind randomized trials with fluoxetine and desipramine were crossed over to treatment with the other drug under open conditions for 6 weeks. Response was considered if patient's final Hamilton depression scale score decreased $50 \%$ or more from baseline. Results: No significant differences were found by drug treatment or sequence of treatment. Ten of the 18 patients (55.5\%) were responders to both fluoxetine and desipramine, $3(16.6 \%)$ were resistant to fluoxetine, $3(16.6 \%)$ to desipramine and $2(11.1 \%)$ to both drugs. Discussion: These data suggest that among first major depressive episode outpatients fluoxetine and desipramine are equally effective. In patients who have been non-responders to one of the studied drugs, the other one is strikingly effective; this kind of treatment maneuver should be considered in such patients.
\end{abstract}

KEY WORDS: Fluoxetine. Desipramine. Major depression. First episode. Crossover study.

\section{Introduction}

Ten years after the appearance of the first antidepressants (monoamine oxidase inhibitors and tricyclic antidepressants) and with the advances achieved, Joseph J. Schildkraut (1934-2006) published in 1965 what today is known as the catecholaminergic hypothesis of depression ${ }^{1}$. Since its publication, this theory, which associates depression with low levels of neurotransmitters, was accepted to explain not only the neurobiochemistry of depression, but also the effect of antidepressant drugs. This theory revolutionized our understanding about the function of neurotransmitters in affective disorders, laying the foundations for their basic and clinical investigation. Briefly, this hypothesis postulates that, in depression, the function of the dopamine, noradrenaline and indolamine serotonin monoamines is decreased ${ }^{2}$. In support of this, different studies have shown changes in plasma, urine and cerebrospinal fluid concentrations of these neurotransmitters and their metabolites, changes in the density of neuroreceptors in platelets and neurons, flattened curves in neuroendocrine challenges and early relapses with the blockage of restriction enzymes for neurotransmitter synthesis in patients who had achieved depression remission with antidepressant treatment ${ }^{3}$. The existence of depression cases where noradrenergic, serotoninergic or dopaminergic negative balance is predominant has been also postulated. Patients with these subtypes of depression

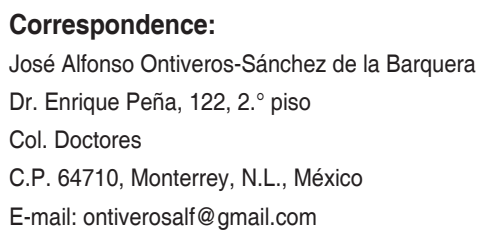

Date of reception: $13-07-2016$

Date of acceptance: 28-11-2016 DOI://dx.doi.org/10.24875/GMM.M18000057
Gac Med Mex. 2017;153:621-627

Contents available at PubMed www.gacetamedicademexico.com 
hypothetically would respond better to antidepressant drugs with noradrenergic, serotoninergic and dopaminergic effects, depending on the case. However, clinical studies on the effect of antidepressants with different mechanisms of action show contradicting results, and there are no clear biological or clinical parameters that can predict the results of different antidepressant treatments ${ }^{4}$. It should be noted that, in the light of current knowledge, the catecholaminergic theory appears to be simplistic and has been the subject of numerous criticism and revisions. In fact, today it would be very daring to think that the deficit of a single neurotransmitter would be present in most depressed patients. However, knowing if there are groups of patients that may respond better to drugs with different mechanisms of action continues to be important. However, crossover trials, where the same patient is exposed to two drugs in order to differentiate the responses to antidepressants with different mechanisms of action are scarce in the literature. Nevertheless, this approach has been employed in groups of patients with obsessive-compulsive disorder ${ }^{5,6}$ and dysmorphic body disorder ${ }^{7}$, which have been found to respond better to antidepressant drugs with serotoninergic, but not noradrenergic effect.

The present study was designed based on the hypothesis that there are subgroups of patients with major depression disorder who respond better to antidepressants with serotoninergic or noradrenergic affect. For this purpose, we treated two groups of patients with fluoxetine, a selective serotonin reuptake inhibitor (SSRI), and desipramine, a potent tricyclic selective norepinephrine reuptake inhibitor (SNRI), in a crossover fashion. We selected patients who were experiencing a first episode of major depression who were antidepressant therapy-naive. One group of patients was initially assigned to fluoxetine and then to desipramine, and the other received first desipramine and then fluoxetine. Each drug was administered for 6 weeks.

\section{Method}

Patients between 18 and 65 years of age, who met the DSM-III- $\mathrm{R}^{8}$ criteria for a first major depression episode, without previous experience with antidepressant treatments or treatment with concomitant psychoactive drugs, were included. Patients had to have moderately severe disease (clinical global impression of severity higher than or equal to 4 points) and a score of 18 or higher in the Hamilton rating scale for depression. Patients with other psychiatric diagnoses, including any psychotic disorder, schizophrenia, bipolar disorder, anxiety disorders, alcohol or drug abuse or dependence (DSM-III-R), unstable or relevant medical conditions, pregnant or breastfeeding patients (all women of childbearing age had to use a double-barrier contraceptive method) and patients on psychotherapy or with suicide risk were excluded. Patients had to have spent 2 weeks without psychoactive treatments. Study participants were included in a double-blind fashion in two groups: one, where they received fluoxetine, and another where they received desipramine and, at completion, they were invited to participate in the crossover study. All patients signed an informed consent letter prior to being included in the study. In an initial phase of the study, the patients received treatment with placebo for at least one week (maximum two) in a single-blind fashion. At the end of this phase, those patients who continued with 18 points or more in the first 17 items of the Hamilton rating scale for depression and who did not improve by $20 \%$ or more, received active treatment. The group of patients that took fluoxetine for 6 weeks received 6 weeks of desipramine, while the other group that first took desipramine received fluoxetine for an equal period of time. Depression severity and clinical evolution were studied with the 21-point HAMD scale, the 8-point clinical global impression of severity (CGI-S) scale and the clinical global impression of improvement (CGI-I) scale. The HAMD scale was completed at the screening visit prior to treatment initiation, after the placebo single-blind phase and at the end of each 6-week crossover treatment stage. The CGI-S and CGI-I scales were completed at baseline visit and at days 14,28 and 42 of each treatment course. Patients with a reduction equal to or higher than $50 \%$ from baseline score in the HAMD scale and a CGI-I score equivalent to "improved" or "much improved" were considered responders. For final evaluations, only those patients who completed 84 days of continuous treatment in the study (42 days with fluoxetine and 42 days with desipramine) were considered. Fluoxetine was administered at a fixed dose of $20 \mathrm{mg} /$ day in the morning and desipramine was administered at night according to the following scheme: $25 \mathrm{mg}$ on the first 3 days, $50 \mathrm{mg}$ for 4 more days, and $100 \mathrm{mg}$ for 1 week, followed by optional $50-\mathrm{mg}$ increases every week until the maximum dose of $250 \mathrm{mg} / \mathrm{day}$ was reached, looking for maximum improvement and tolerability. Categorical data statistical analysis was carried out using the chi-square test for continuous data, 
with the two-proportion test also being used. To compare patient data on both study treatments, the Mann-Whitney test or Student's t-test were used. The Kruskal-Wallis test was used to compare HAMD and $\mathrm{GCl}-\mathrm{S}$ baseline values with the values obtained in the course of treatments. Proportions are reported with their standard deviations.

\section{Results}

Twenty-three patients who had completed 6 weeks of treatment (12 patients with fluoxetine and 11 with desipramine) were included in the study. These 23 patients had an age of $36.6 \pm 12.89$ years, $12(66.6 \%)$ were females, $14(77.7 \%)$ were married and 3 patients (16.6\%) had a college education. Of the 23 patients, 18 completed the 12 weeks of crossover treatment, 9 received the desipramine-fluoxetine sequence and 9 the fluoxetine-desipramine sequence. Both groups did not differ in terms of age, gender distribution, vital signs (except for diastolic blood pressure), weight, depression severity and depressive episode duration (Table 1).

The 18 patients who completed the crossover study and the 5 who discontinued it prematurely did not differ as regards demographic and clinical variables. However, patients who first received fluoxetine had more severe depression $(26.2+3.9)$ than those who received desipramine $(21.5+3.7)$ (Mann-Whitney's $z=2.66 ; p=0.01)$ in the HAMD 21 scale, with no differences between both groups prior to the single-blinded placebo phase. After desipramine, patients who received fluoxetine had lower scores in the CGI-S scale $(p<0.05)$.

Both groups of studied patients showed a statistically significant reduction in the HAMD and CGI-S scores and improvement throughout the study (Table 2 and Figs. 1 and 2). Patients regarded as responders according to study criteria were 13 for fluoxetine and 13 for desipramine (fluoxetine [7] and desipramine [9] sequence; desipramine [4] and fluoxetine [6] sequence. Of the 18 study subjects, $10(55.5 \%)$ responded to both studied antidepressants, $2(11.1 \%)$ responded only to the SSRI fluoxetine and 2 to the SNRI desipramine (11.1\%). Three patients (16.6\%) were non-responders to fluoxetine and $3(16.6 \%)$ to desipramine, while 2 patients $(11.1 \%)$ did not respond to both antidepressants. Table 3 shows CGI-S scale final scores in the groups of responder and non-responder patients at the end of weeks 6 and 12 for both studied sequences.

The 18 patients who completed the study received the following desipramine-treatment dose: fluoxetine-desipramine sequence, $188.8 \pm 33.3 \mathrm{mg} / \mathrm{day}$, desipramine-fluoxetine sequence, $205.5 \pm 48.1 \mathrm{mg} /$ day; the dose range was 125 to $250 \mathrm{mg} /$ day $(\mathrm{t}=82$ : $\mathrm{df}=14$; $p>0.17$, non-significant). All patients were treated with $20 \mathrm{mg} /$ day of fluoxetine. Of the 23 who started the study, the reasons for early discontinuation were: adverse events (two patients with fluoxetine and one with

Table 1. Treated patients' demographic and clinical differences by treatment sequence, prior to treatment

\begin{tabular}{|c|c|c|c|c|c|c|c|}
\hline & $\begin{array}{l}\text { FLX/DMI } \\
\text { Sequence } \\
\text { Average }\end{array}$ & SD & $\begin{array}{l}\text { DMI/FLX } \\
\text { Average }\end{array}$ & SD & Test & 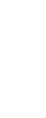 & $p$ \\
\hline & $N=9$ & & $N=9$ & & & 은 & \\
\hline Age (years) & 36.3 & & 34.3 & 10.9 & $t=0.490$ & $\stackrel{1}{2}$ & $0.63^{*}$ \\
\hline Males & $2(22.2 \%)$ & & $4(44.4 \%)$ & & $z=1.57$ & है & $\mathrm{NS}^{+}$ \\
\hline Weight (kg) & 63.5 & 9.1 & 69.1 & 12.2 & $t=1.09$ & $\frac{ᄃ}{\circ}$ & $0.29^{*}$ \\
\hline Pulse & 82.5 & 10.7 & 78.8 & 12.7 & $t=0.668$ & 을 & $0.51^{*}$ \\
\hline Systolic blood pressure & 123.5 & 23.1 & 122.4 & 20.1 & $t=0.110$ & $\frac{}{2}$ & $0.91^{*}$ \\
\hline Diastolic blood pressure & 81.2 & 4.4 & 72.01 & 9.9 & $t=2-52$ & $\frac{n}{\mp}$ & $0.02^{*}$ \\
\hline Depressive episode duration (weeks) & 53.1 & 48.3 & 45.8 & 19.1 & $t=0.42$ & $\circ$ & $0.68^{*}$ \\
\hline CGI-S & 5 & 7.71 & 4.7 & 7.71 & $z=1.0$ & 을 & $0.33^{\dagger}$ \\
\hline HamD & 25.4 & 7.42 & 23.7 & 7.49 & $z=1.15$ & $\stackrel{0}{z}$ & $0.24^{\ddagger}$ \\
\hline $\begin{array}{l}\text { *Student's t-test. } \\
\text { †Difference of proportion. } \\
\text { †Mann-Whitney's test. } \\
\text { CGI-S: clinical global impression of severity; DMI: d }\end{array}$ & ELX: fluoxetine & ilton r & ep & ant. & ion. & & \\
\hline
\end{tabular}


Table 2. Hamilton rating scale for depression results in patients by fluoxetine-desipramine and desipramine-fluoxetine treatment sequences

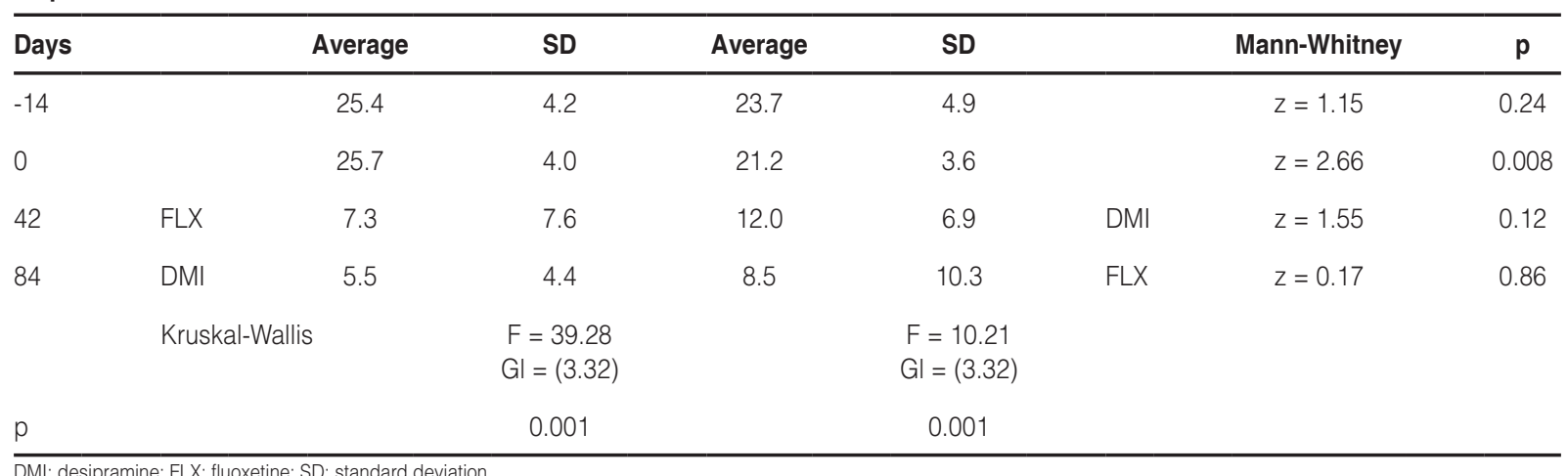

DMI: desipramine; FLX: fluoxetine; SD: standard deviation

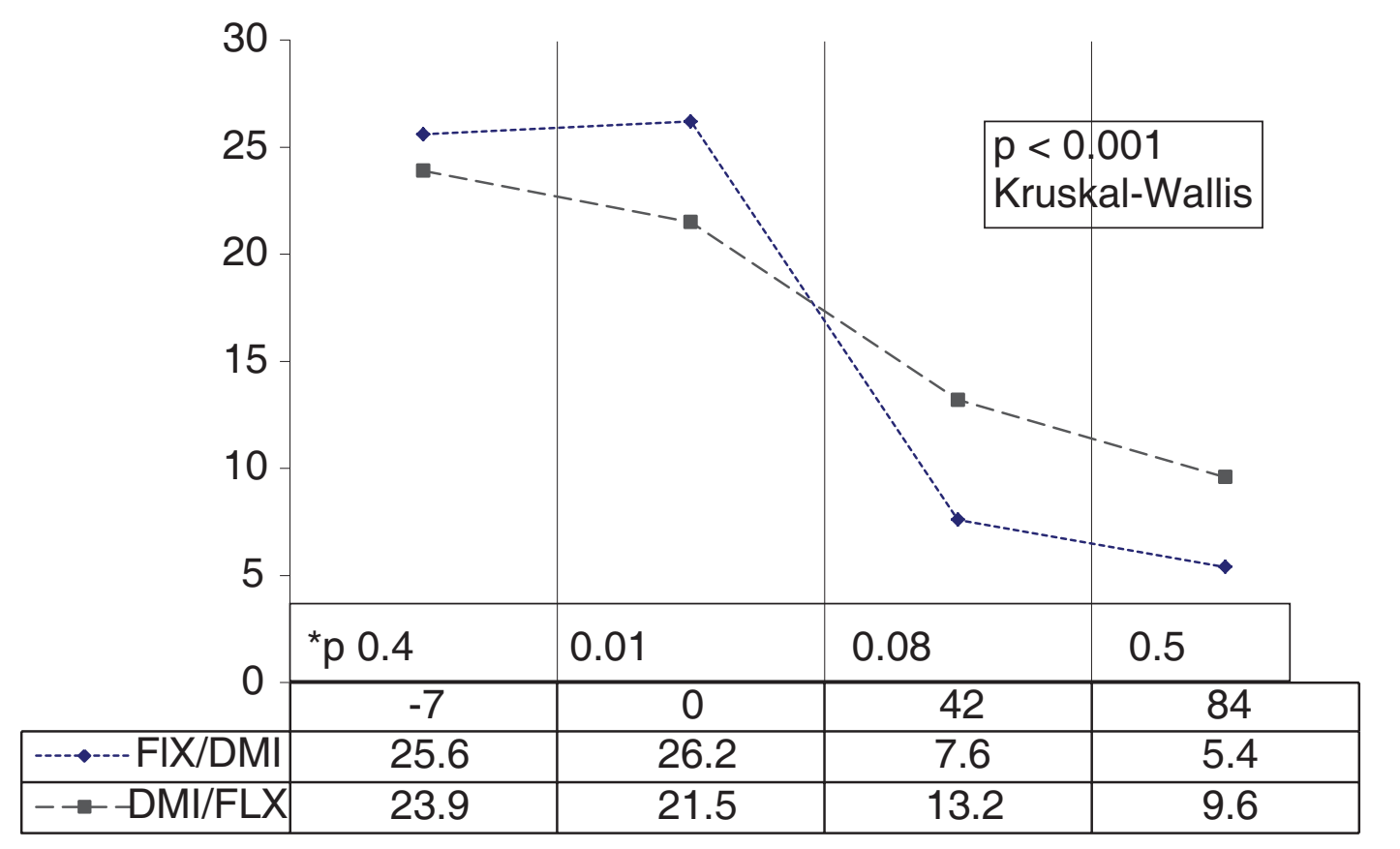

Figure 1. Hamilton rating scale for depression scores comparison in patients treated with the fluoxetine-desipramine (FLX/DMI) and desipramine-fluoxetine (DMI/FLX) sequences.

*Mann-Whitney's test.

desipramine), lack of efficacy and adverse events (one patient with fluoxetine) and loss to follow-up (one patient with desipramine). A statistically significant change in heart rate was observed with desipramine $(95.3 \pm 5.4)$ in comparison with fluoxetine $(76.1 \pm 9.1$; $t=5.08 ; d f=13 ; p=0.001$ ). Table 4 shows the adverse events observed during the study and the time to reach statistically significant differences. For each adverse event reported with desipramine, there were 1.73 adverse events with fluoxetine (test of proportion $p<$ 0.05). The most common adverse events with fluoxetine were headache (at week 4), insomnia and hot flashes (at week 8), and nervousness (at week 10). Dry mouth was the only statistically more common adverse event with desipramine (at weeks 10 and 12). Serious adverse events were reported by 6 patients: 3 with fluoxetine and 3 with desipramine.

\section{Discussion}

The few crossover studies published on major depression have explored the existence of patient subgroups that might respond better to drugs with serotoninergic of noradrenergic effects. Some of these studies have included neurobiochemical and clinical variables that might differentiate between groups of patients. Thus, in a study of 65 hospitalized patients with "endogenous" depression, low levels of two serotonin metabolites 

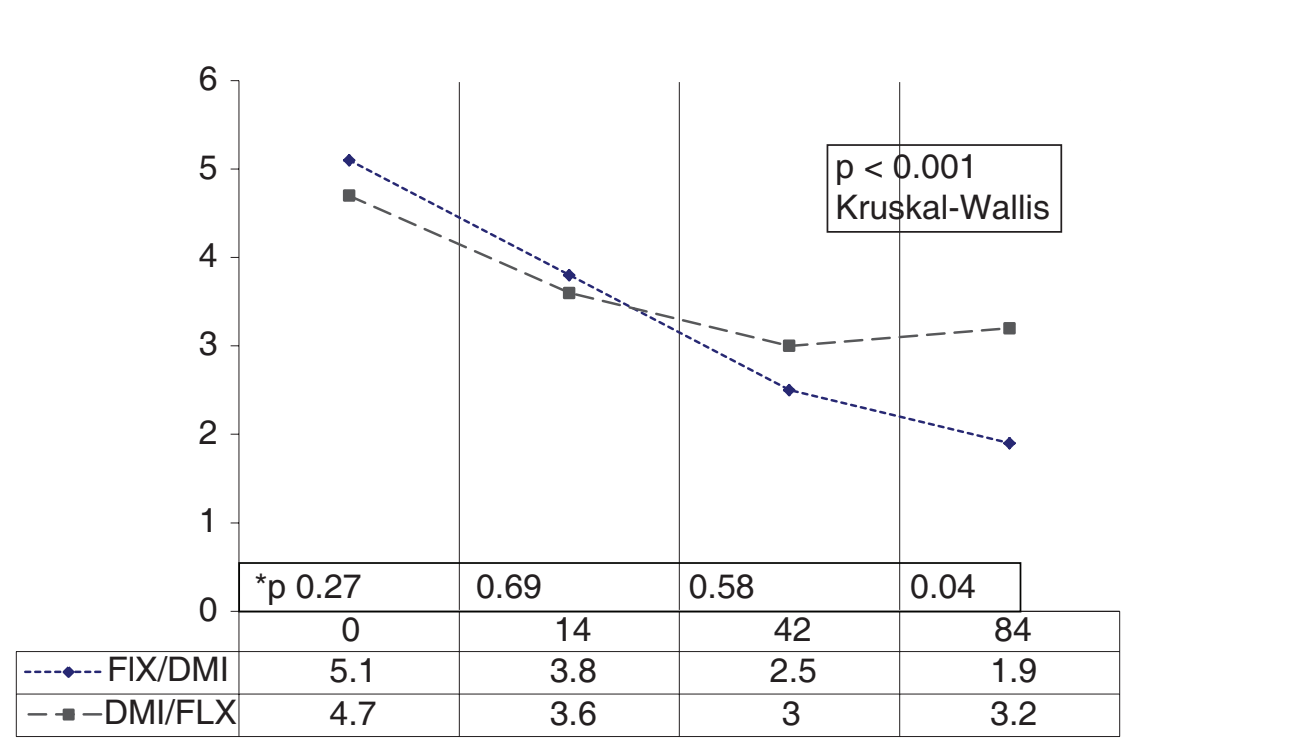

Figure 2. Average scores in the clinical global impression of severity scale in patients treated with the fluoxetine-desipramine (FLX/DMI) and desipramine-fluoxetine (DMI/FLX) sequences.

Table 3. Response to the treatment with fluoxetine and desipramine

\begin{tabular}{|c|c|c|c|c|}
\hline \multirow[t]{2}{*}{ CGI-I } & \multicolumn{2}{|c|}{$\begin{array}{l}\text { Fluoxetine } \\
\text { Desipramine }\end{array}$} & \multicolumn{2}{|c|}{$\begin{array}{l}\text { Desipramine } \\
\text { Fluoxetine }\end{array}$} \\
\hline & N (\%) & $\mathrm{N}(\%)$ & $\mathrm{N}(\%)$ & $\mathrm{N}(\%)$ \\
\hline Very much improved & $7(78)$ & $8(89)$ & $3(33)$ & $6(67)$ \\
\hline Much improved & $1(11)$ & $1(11)$ & $2(22)$ & $1(11)$ \\
\hline Slightly improved & $1(11)$ & 0 & $3(33)$ & 0 \\
\hline No change & 0 & 0 & 0 & $2(22)$ \\
\hline Slightly worse & 0 & 0 & $1(11)$ & 0 \\
\hline $\begin{array}{l}\text { Responders } \\
\text { HamD }<50 \% \text { from baseline }\end{array}$ & $7(78)$ & $9(100)$ & $4(44.5)$ & $6(67)$ \\
\hline $\begin{array}{l}\text { Non-responders } \\
\text { HamD } \geq 50 \% \text { from baseline }\end{array}$ & $2(22)$ & $0(0)$ & $5(55.5)$ & $3(33)$ \\
\hline
\end{tabular}

Table 4. Adverse events with fluoxetine and desipramine (statistically significant differences)

\begin{tabular}{lcccc}
\hline Event & $\begin{array}{c}\text { Fluoxetine } \\
\mathbf{N}(\%)\end{array}$ & $\begin{array}{c}\text { Desipramine } \\
\mathbf{N}(\%)\end{array}$ & $\begin{array}{c}\text { Difference } \\
\text { per week }\end{array}$ & $\mathbf{p}$ \\
\hline Dry mouth & $9(7.3)$ & $16(22.5)^{*}$ & 10,12 & 0.05 \\
Headache & $15(2.2)^{*}$ & $7(9.8)$ & 4 & 0.05 \\
Nervousness & $10(8.3)^{*}$ & $2(2.8)$ & 10 & 0.05 \\
Hot flashes & $6(4.9)$ & $4(5.6)^{*}$ & 8 & 0.05 \\
Insomnia & $4(3.2)^{*}$ & $0(0.0)$ & 8 & 0.05 \\
Total & $123^{*}(100)$ & $71(100)$ & 12 & 0.05 \\
\hline
\end{tabular}

*Highest z-values, test of proportion.

(5-HIAA and HVA) were detected in the cerebrospinal fluid of patients who responded better to the SSRI zimelidine, whereas patients with high values of $\mathrm{HMPG}$ (a norepinephrine metabolite) in the cerebrospinal fluid responded better to desipramine $e^{9-14}$. The existence of groups of depressive patients with low serotonin central values, and patients with a tendency towards HVA higher values who respond better to the SNRI desipramine has been suggested ${ }^{9,14,15}$, although these observations have not been confirmed in all studies ${ }^{16}$.

Several crossover studies have given the second treatment only to groups of patients with resistance to the first administered antidepressant, or have included mixed populations of depressive patients and subjects with bipolar depression ${ }^{17}$. Thus, the first double-blind crossover study reported in the literature, carried out with the SSRI zimelidine and the SNRI desipramine for 4 weeks in hospitalized patients who met "endogeneity" criteria for depression, and one of the objectives of which was to assess pharmacokinetic, neuroendocrine and behavioral parameters ${ }^{14}$, included three patients with a history of mania, out of which one was excluded owing to psychotic worsening and one more developed mania with desipramine. In this study, the authors reported antidepressant efficacy in $60 \%$ of patients $(\mathrm{N}=3)$ with zimelidine and in $30 \%$ of patients with desipramine $(N=2)$. In that regard, our study is different from other crossover studies with SSRI and SNRI, since it is the first one to compare fluoxetine and desipramine, with all patients receiving both drugs for at least 6 weeks and with patients with a first major depressive episode being included.

Humble $^{4}$ suggests that, in the selection of an antidepressant drug, the clinician must observe the overall response of his/her patients with major depression 
and the possible relationship between the drug's biochemical effect and its effects on specific symptoms. This is more important when a drug has failed to improve the patient and a new one has to be supplied, when adverse events force treatment change or when combination of two antidepressants is considered. Although there is no consensus, in different comparative trials with antidepressants with predominantly serotoninergic or noradrenergic effects, patients with higher motor retardation have been observed not to respond well to serotoninergic drugs, but to do it to noradrenergic drugs ${ }^{18,19}$. These cases include patients with melancholic depression ${ }^{20,21}$. Good responses to the noradrenergic drug maprotiline have been reported to be correlated with a lower number of previous depressive episodes and duration in years since the first episode, whereas with zimelidine, the best results were observed when the patients had more previous depressive episodes ${ }^{15}$; however, these data have not been corroborated in other studies ${ }^{22}$.

The rate of general antidepressant response to any drug is close to $75 \%^{23}$. Our crossover study supports the observation that depressive patients could be classified according to their responses to serotoninergic and noradrenergic drugs in three subgroups: 1) a large group ( $55 \%$ in our study) of cases that respond to both types of antidepressants; 2) a group of patients (22\% in our study) that respond to a single one of them (11\% to SSRIs, $11 \%$ to SNRIs), and 3) a group of patients that are resistant to both drugs (11\% in our study). When patients who responded to both drugs $(55 \%)$ and those who only responded to one $(22 \%)$ were added, clinical efficacy for fluoxetine and desipramine was $77.7 \%$. It should be noted that this rate is higher than that reported by Bowden et al. ${ }^{24}$ in a 6 -week double-blind trial, where $64 \%$ responded to fluoxetine and $68 \%$ to desipramine. Lingjaerde et al. ${ }^{12}$ and Äberg-Wistedt ${ }^{10}$ found a bimodal response tendency (all-or-nothing) to the SSRI zimelidine and to desipramine in double-blind crossover studies, which is a situation we didn't find in our study and that might be explained by the difference in patient populations. The response of SSRI and SNRI drugs-resistant patients deserves to be commented within the context of the present work. Reports in the literature show response rates of $43 \%$ to $75 \%$ when patients that are resistant to a SSRI are switched to a SNRI and vice-versa ${ }^{23}$. Emrich et al. ${ }^{22}$ compared the SSRI fluvoxamine and the SNRI oxaprotiline in 71 tricyclic antidepressant-resistant patients. Non-responder patients were crossed to the other treatment and responses of $33 \%$ (21 of 64 patients) were obtained with oxaprotiline, but only of $4 \%$ (2 of 56 patients) with fluvoxamine. In contrast, a comparative study with maprotiline $(\mathrm{N}=35)$ and zimelidine $(\mathrm{N}=40)$, where patients with no improvement were switched to the other treatment, found that 7 patients of each group failed to respond at 4 weeks of treatment $(20 \%$ for maprotiline and $17.5 \%$ for zimelidine) and, out of hem, 6 patients in each group (17\% with maprotiline and $15 \%$ with zimelidine) were improved ${ }^{12}$. White et al. ${ }^{19}$, in 12 desipramine-resistant patients, observed that, when switched to the SSRI fluvoxamine in a double-blind fashion, $75 \%$ experienced an improvement, and Delgado et al. ${ }^{25}$, in an open-label study with $7 \mathrm{pa}$ tients who failed to respond to desipramine, reported a response in $71 \%$ when treated with fluvoxamine. Tricyclic antidepressant-resistant patients respond at a rate of $60 \%$ when switched to a SSRI, and $65 \%$ of patients who are resistant to a SNRI improve with tricyclic SNRIs such as nortriptyline, desipramine or oxtremoline $e^{21,26-28}$. In our study, $75 \%$ of desipramine-resistant patients were improved with fluoxetine, and $75 \%$ of those who were resistant to fluoxetine were improved with desipramine. Our results are consistent with those of studies in resistant patients.

Our findings in this 12-week crossover study with fluoxetine and desipramine should be evaluated in the light of the limitations inherent to an open-label study with a small sample, as it often occurs in crossover studies, where there was $21.7 \%$ of early discontinuations. In addition, desipramine plasma concentrations were not assessed, although the patients received the maximum tolerated dose of $205.5 \mathrm{mg}$ per day on average (range: 125 to $250 \mathrm{mg} /$ day). We ignore if a higher dose of fluoxetine might have improved a larger number of patients. Patients who first received fluoxetine and then desipramine likely had higher desipramine concentrations for at least 3 weeks $^{29,30}$, owing to cytochrome P450 2D6 subunit inhibition by fluoxetine and its metabolite norfluoxetine. Accordingly, adverse events such as hot flashes and insomnia occurred more commonly when patients were switched from fluoxetine to desipramine. Notwithstanding, antidepressant rapid switch is a recommended and well-tolerated maneuver ${ }^{31}$. Finally, as it occurs in crossover studies, a "carry forward" effect of the first administered treatment effect cannot be ruled out, which was evinced by a statistically significant progressive decrease in the Hamilton depression rating scale and CGI-S scores with both treatment sequences. 
The present study on SSRIs and SNRIs differentiated antidepressant effect sheds light on the responses to these pharmacological agents and supports that there are depressive syndromes that respond better to noradrenergic and serotoninergic drugs, and can guide the clinician in the selection of antidepressant treatment in SSRI and SNRI-resistant patients. Further crossover studies are required with different antidepressants with serotoninergic and noradrenergic effects in order to confirm our findings.

\section{Finding}

Partially supported by the Sistema Nacional de Investigadores 11503 subvention.

\section{References}

1. Green Al, Schatzberg AF. Obituary. Joseph J. Schildkraut, 1934-2006 Neuropsychopharmacology. 2007;32:1855-6.

2. Schildkraut, JJ. The catecholamine hypothesis of affective disorders: a review of supporting evidence. Am J Psychiatry. 1965;122:509-22.

3. Goldstein DJ, Potter WZ, Ciraulo DA, et al. Biological theories of depression and implications for current and new treatments. En: Ciraulo DA Shader RI, editores. Pharmacotherapy of depression. $2^{\text {nd }}$ ed. New York: Human Press; 2011. p. 1-32.

4. Humble M. Noradrenaline and serotonin reuptake inhibition as clinical principle: a review of antidepressant efficacy. Acta Psychiatr Scand. 2000;101(Suppl 402):28-36

5. Riddle MA, Scahill L, King RA, et al. Double-blind, crossover trial of fluoxetine and placebo in children and adolescents with obsessive-compulsive disorder. J Am Acad Child Adolsc Psychiatr. 1992;31:1062-9.

6. Goodman WK, Price LH, Delgado PL, et al. Specificity of serotonin reuptake inhibitors in the treatment of obsessive-compulsive disorder. Comparison of fluvoxamine and desipramine. Arch Gen Psychiatry. 1990;47:577-85

7. Hollander E, Allen A, Kwon J, et al. Clomipramine vs desipramine crossover trial in body dysmorphic disorder. Selective efficacy of a serotonin reuptake inhibitor in imagined ugliness. Arch Gen Psychiatry. 1999;56:1033-9

8. American Psychiatric Association. Diagnostic and statistical manual of mental disorders. $3^{\text {rd }}$ edition-revisited. Washington, DC: American Psychiatric Press; 1987.

9. Äberg-Wisted A, Jostell KG, Ross SB, et al. Effects of zimelidine and desipramine on serotinin and noradrenaline uptake mechanism in relation to plasma concentrations and to therapeutic effects during treatment of depression. Psychopharmacology. 1981;74:297-305.

10. Äberg-Wistedt A. A double blind study of zimelidine, a serotonin uptake inhibitor, and desipramine, a noradrenaline uptake inhibitor, in endogenous depression. I. Clinical finding. Acta Psychiatr Scand. 1982;66:50-65.
11. Äberg-Wistedt A. Comparison between zimelidine and desipramine in endogenous depression. A cross-over study. Acta Psychiatr Scand. 1982;66:129-38

12. Lingjaerde $\mathrm{O}$, Bratfos $\mathrm{O}$, Bratlid $\mathrm{T}$, et al. A double-blind comparison of zimelidine and desipramine in endogenous depression. Acta Psychiatr Scand. 1983;68:22-33

13. Nystgröm $C$, Hällström $T$. Comparison between a serotonin and a noradrenaline reuptake blocker in the treatment of depressed outpatients. A cross-over study. Acta Psychiatr Scand. 1987;75:377-82.

14. Äberg A. Controlled crossover study of a $5 \mathrm{HT}$ uptake inhibiting and an NA uptake inhibiting antidepressant. Acta Psychiatr Scand. 1981;63(Suppl 190):224-55.

15. van Praag HM. New evidence of serotonin-deficient depressions. Neuropsychobiology. 1977;3:56-63.

16. Burns RA, Lock T, Edwards DR, et al. Predictors of response to amine-specific antidepressants. J Affect Disord. 1995;35:97-106.

17. Potter WZ, Calil HM, Extein I, et al. Specific norepinephrine and serotonin uptake inhibitors in man: a crossover study with pharmacokinetic, biochemical, neuroendocrine and behavioral parameters. Acta Psychiatr Scand Suppl. 1981;290:152-65.

18. Nyström $\mathrm{C}$, Hällström T. Comparison between a serotonin and a noradrenaline reuptake blocker in the treatment of depressed outpatients. A cross-over study. Acta Psychiatr Scand. 1987;75:377-82.

19. White K, Wykoff W, Tyness LL, et al. Fluovoxamine in the treatment of tricyclic-resistant depression. J Psychatr Neurosci. 1990;15:156-8.

20. Szegedi A, Wetzel H, Angersbach D, et al. A double-blind study comparing paroxetine and maprotiline in depressed outpatients. Pharmacopsychiatry. 1997;30:97-105

21. Nolen WA, van de Putte JJ, Dijken WA, et al. Treatment strategy in depression. I. Non-tricyclic and selective reuptake inhibitors in resistant depression: a double-blind partial crossover study on the effects of oxaprotiline and fluvoxamine. Acta Psychiatr Scand. 1988;78:668-75.

22. Emrich $\mathrm{H}$, Berger $\mathrm{M}$, Riemann $\mathrm{D}$, et al. Serotonin reuptake inhibition versus norepinephrine reuptake inhibition: a double-blind differential therapeutic study with fluvoxamine and oxaprotiline in endogenous and neurotic depressives. Pharmacopsychiatrica. 1987;20:60-3.

23. Thase ME, Rush AJ. Treatment-resistant depression. En: Bloom FE, Kupfer DJ, editors. Psychopharmacology, the fourth generation of progress. New York: Raven Press; 1995. p. 1081-97.

24. Bowden CL, Schatzberg AF, Rosenbaum A, et al. Fluoxetine and desipramine in major depressive disorder. J Clin Psychopharmacol. 1993; 135:305-11.

25. Delgado PL, Price LH, Charney DS, et al. Efficacy of fluovoxamine in treatment-refractory depression. J Affect Disord. 1988;15:55-60.

26. Souery D, Serretti A, Calati R, et al. Citalopram versus desipramine in treatment resistant depression: effect of continuation or switching strategies. A randomized open study. World J Biol Psych. 2011;12:364-73.

27. Papakostas GI, Fava M. Pharmacotherapy for depression and treatment-resistant depression. USA: World Scientific Publishing Co. Pte. Ltd 2010.

28. Nierenberg AA, Papakostas GI, Petersen T, et al. Nortriptyline for treatment-resistant depression. J Clin Psychiatry. 2003;64:35-9.

29. Suckow RF, Roose SP, Cooper TB. Effect of fluoxetine on plasma desipramine and 2-hidroxydesipramine. Biol Psychiatry. 1992;31(2 Suppl): 200-4.

30. Preskorn SH, Alderman J, Chung M, et al. Pharmacokinetics of desipramine coadministered with sertraline or fluoxetine. J Clin Psychopharmacol. 1994;14(2 Suppl):90-8.

31. Van Ameringen M, Mancini C. Adverse effects of switching from fluoxetine to desipramine (letter). Can J Psychiatry. 1992;37(4 Suppl):278. 